\title{
Structural Mechanical Analysis of MEMS Micromirror using COMSOLMultiphysics
}

\author{
M.Archana ${ }^{1}$, Mithali Manohar ${ }^{2}$, G.Manimegalai ${ }^{3}$ \\ Department of electronics and communication Engineering, TejaaShakthi Institute of technology for \\ Women. Coimbatore. \\ EmailID:archu.techvivid@gmail.com,batch4mems@gmail.com
}

\begin{abstract}
MEMS Micromirrors are used in various applications like Digital light projector (DLP), Highdefinition (HD) display, endoscopic Optical Coherent Tomography and also in defense applications. This paper deals with the analysis of structural mechanical properties of electrostatically driven prestressedMicromirrorusing COMSOL Multiphysics $4.3 \mathrm{~b}$ software. The proposed design was compared for the lift-off stress generated at the edges due to the plating process and the associated displacement at a given prestress level.
\end{abstract}

Keywords: MEMS, Micromirrors, Cantilever,COMSOLMultiphysics, Serpentine beam.

\section{Introduction}

The development of MEMS technology shows a huge step forward in biomedical, automotive and communication industries. MEMS Micromirror technology is highly versatile and adaptable to various applications. Electrostatic driven MEMS mirrors areused in applications where a high pointing stability is required ${ }^{[2],}{ }^{[3]}$ and it is the solution of choice foradvancedfibre optic light processing. In this paper, a Micromirror model is simulated using COMSOL Multiphysics 4.3b; the results obtained from the simulation help to reduce the displacement associated with the stress developed due to the plating process during the fabrication of MEMS Micromirror.

\section{Existing Design Of Mems Mirror}

The existing model consists of a square shapedMicromirror with four straight shaped cantilever beams as actuators ${ }^{[1]}$. The initial stress was set as $5[\mathrm{GPa}]$ andthe distribution of the stress over the entire surface was made as complex as possible, as advised from the COMSOL proposed model.

The results obtained for different material combinations showed that the best material combination was Aluminium 3003 for the cantilever legs and structural steel for the Micromirrorsubstrate ${ }^{[1]}$ asit reduced the stress at the edges and cantilever lift-off. The reason for selecting steel for the Micromirror substrate is to reduce the surface deformation as it is stiffer than Aluminium.

\section{Proposed Design}

In the existing system it has been shown that the surface deformation and cantilever was at high stress level. Although the stress was reduced with the best material combination, the lift off stress and the displacement was still higher for the design of devices at micro scale. So the performance of the Micromirror was improved by reducing the stress on the cantilever edges by modifying the straight shaped cantilever beam design to a serpentine or zigzag shaped beam. Figure 1 shows the structure of serpentine beam with a square shaped Micromirror.

The design was simulated using COMSOL Multiphysics $4.3 \mathrm{~b}^{[4]}$ with an initial stress of $5[\mathrm{GPa}]$.The graph of prestress versus displacement was plotted (Figure 3).Different values of prestress were taken, from 0 to $10 \mathrm{e}^{9}$, to obtain the level of dependence of the displacement on the stress. The results were then compared and tabulated (Table 1). 


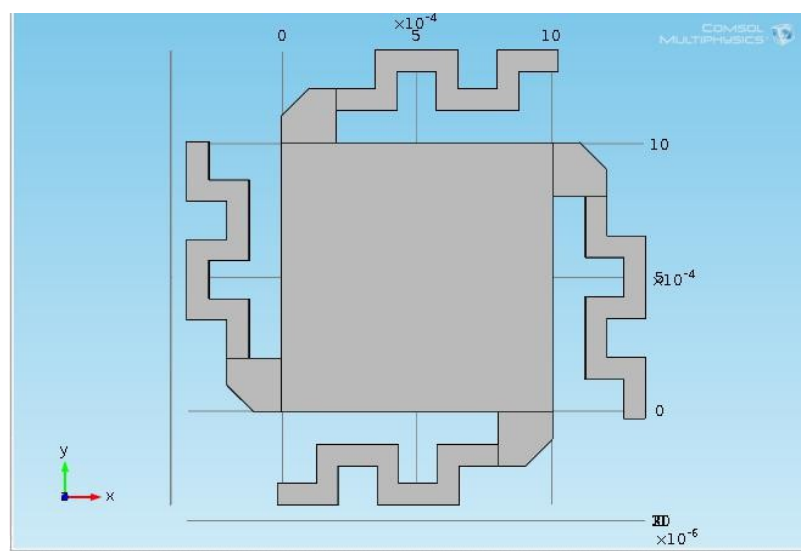

Figure 1 Proposed structure using COMSOL

\section{Results And Discussion}

The lift-off level and the associated stress for the Micromirror with S-shaped cantilever beams is $36 \times 10^{\wedge}-6 \mathrm{~m}$ and $0.032 \mathrm{~N} / \mathrm{m}^{\wedge} 2$ respectively, which is lesser than that of the Micromirror with straight shaped cantilever beams (lift-off $=50 \times 10^{\wedge}-6 \mathrm{~m}$ and stress level $=0.0543 \mathrm{~N} / \mathrm{m}^{\wedge} 2$ ) as shown in figure 2 .

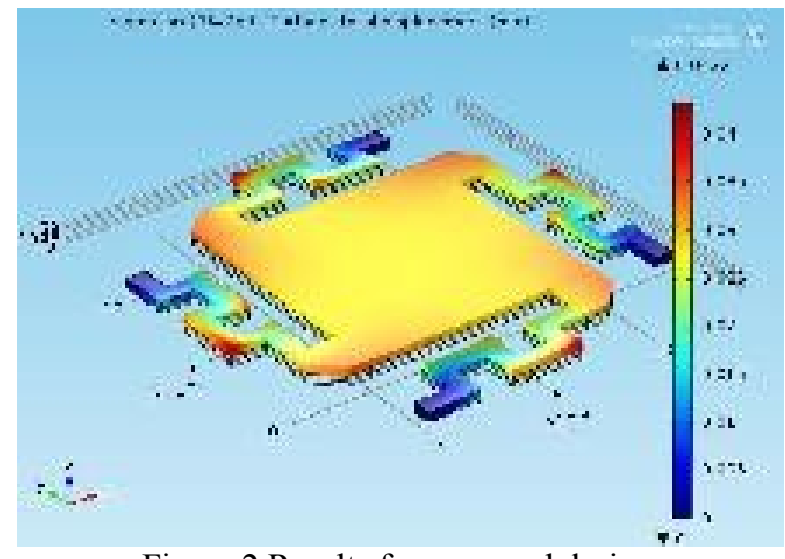

Figure 2 Results for proposed design

The results obtained from the simulation of straight shaped cantilever beams and s-shaped cantilever beams are tabulated.

\begin{tabular}{|c|c|c|c|}
\hline $\begin{array}{c}\text { Micromirror } \\
\text { shape }\end{array}$ & $\begin{array}{c}\text { Cantilever } \\
\text { Shape }\end{array}$ & Lift-off & Stress level \\
\hline square & Straight & $50 \times 10^{-6}$ & 0.0543 \\
\hline square & s-shaped & $36 \times 10^{-6}$ & 0.032 \\
\hline
\end{tabular}

Table 1 Comparison of lift-off and stress level of straight and s-shaped cantilever beams.

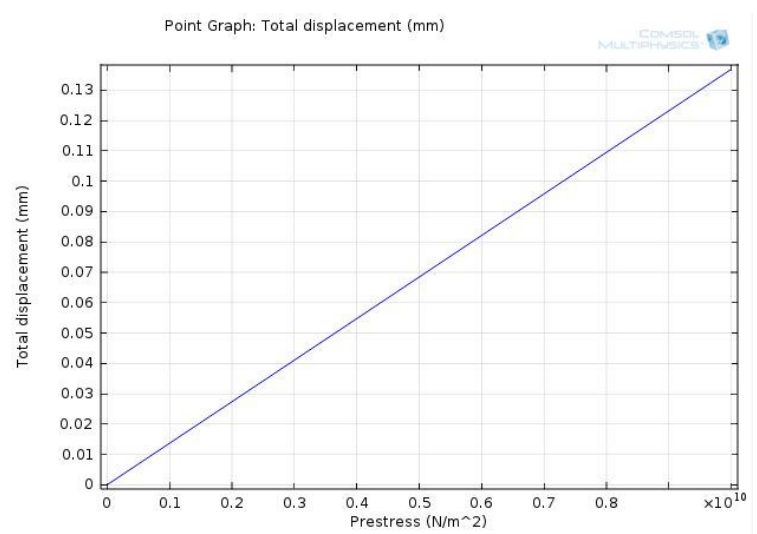

Figure 3 Displacement v/s Prestress curve for an s-shaped cantilevered Micromirror 
The results obtained from Figure 3 have shown that the center point deflection for the s-shaped cantilevered beam is less than the straight shaped cantilevered beam at the provided prestress level. This design with a reduced level of stress is more suitable for fabrication.

\section{Conclusion}

The design proposed in this paper mainly focuses to reduce the lift-off level and the stress, created during the plating process. Hence, the reduced lift-off due to the stress resulted in the reduction of distance between the mirror and the bottom electrode thereby reducing the required actuation voltage. This also helped to achieve large scan angle ${ }^{[5]}$ with relatively small actuating voltage. The design can be further analyzed using static and dynamic parameters that will improve the performance of the Micromirror.

\section{References}

[1]. A COMSOL Model to Analyse the Structural Mechanical Problem in an Electrostatically Controlled Prestressed Micro-Mirror; HazianMamat, AzrulAzlanHamzah, (et.al); World Applied Sciences Journal 26 (7): 950-956, (2013).

[2]. Design and Optimization of an All Optically Driven Phase Correction MEMS Deformable Mirror Device using Finite Element Analysis;V. Mathur ,K. Anglin, V.S. Prasher (et.al) Proceedings of the COMSOL Conference (2009) at Boston.

[3]. MEMS Electrostatic comb actuators with different configurations: A comparison of structure design and materials using COMSOL 3.5a; Swati Kapoor, Dinesh Kumar, (et.al) Proceedings of the COMSOL Conference (2011) at Bangalore.

[4]. COMSOL 4.2a Model Micromirror.

[5]. Design and Analysis of the performance of a Torsional Micromirror for an Optical switching system, Ajay A. Kardak*, Prasant Kumar Patnaik, (et.al); National MEMS Design Centre, Indian Institute of Science, Bangalore.

[6]. Design and optimization of electrostatically actuated Micromirror Anna Thomas,Juny Thomas(et.al); VIT university sensor system technology; vellore; Proceedings from COMSOL Conference(2013),Bangalore.

[7]. Optical MEMS,Wiboolpiyawattanametha and Zhen Qiu,Advanced Imaging research(AIR) centre,(2012); ChulalongkornUniversity,Pathumwan, Thailand.

[8]. A study of the static characteristics of a torsional Micromirror,X.M.Zhanga,Y.L.Lama(et.al);(2003),Division of microelectronics,Nanyang Technological university.Singapore.

[9]. Design.Fabrication and Characterization of a 2-D SOI MEMS Micromirror with side wall electodes for Confocal macroscopeimaging,Yanhui Bai;(2010),A Thesis presented to the University of Waterloo,Ontario,Canada.

[10]. Design, Fabrication and characterization of electrostatically actuated Silicon Micromirrors,Dylanchesbro;(2010),A Thesis presented to the faculty of California polytechnic state University,San Luis Obispo. 